\title{
Paget's disease of Breast
}

Shinjini Singh ${ }^{* 1}$ and Mritunjai Singh ${ }^{2}$

${ }^{1}$ Department of Experimental Therapeutics, MD Anderson Cancer Center, University of Texas, Houston, USA

${ }^{2}$ Department of Medicine, Institute of Medical Sciences, Banaras Hindu University, Varanasi, India

"Corresponding author: Shinjini Singh, Department of Experimental Therapeutics, MD Anderson Cancer center, University of Texas, Houstan, USA; Tel No: 18776326789; E-mail: shinjini0507@gmail.com

Rec Date: 07 Apr, 2016; Acc Date: 08 Apr, 2016; Pub Date: 16 Apr, 2016

Copyright: (C) 2016 Singh S, This is an open-access article distributed under the terms of the Creative Commons Attribution License, which permits unrestricted use, distribution, and reproduction in any medium, provided the original author and source are credited.

\section{Clinical Image}

A 50-year-old postmenopausal female with a history of pain in the left breast presented with the Paget's disease of nipple. The physical examination of the patient revealed discharge from the nipple, which was indrawn. The nipple had redness and scaling. The skin of the nipple was flaky and ulcerated. It had abscess and deformity too. The Paget's disease of the patient had underlying tumor, which was proved by the fact that the lymph nodes were involved. FNAC came out to be malignant and the tumor staging was T3N2M0. Immunohistochemistry (IHC) was carried out on the tissue specimen to evaluate the molecular markers. The tumor came to be positive for ER (3+), PR (2+) and HER2 (3+). These markers are generally associated with a better prognosis. Molecular analysis of the tumor was carried out using Single-Stranded Conformation Polymorphism (SSCP) to evaluate mutation in the p53 gene. P53 was found to be mutated, which was confirmed by direct DNA sequencing. P53 protein was also found to be overexpressed by IHC. All these markers are always associated with more aggressive tumor and poorer survival of the breast cancer $(\mathrm{BC})$ patients. Age at menarche of the patient was 11 years, which is one of the risk factors for causing $\mathrm{BC}$ but she didn't have a family history. Due to this extent of disease, the patient had to undergo mastectomy and complete axillary lymph node dissection.

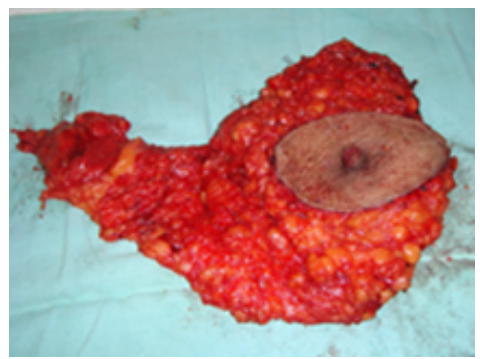

